\title{
Protective role of autophagy in AGE-induced early injury of human vascular endothelial cells
}

\author{
YING XIE $^{1,2^{*}}$, SHOU-JIANG YOU ${ }^{1 *}$, YAN-LIN ZHANG ${ }^{1}$, QIAO HAN ${ }^{1}$, YONG-JUN CAO ${ }^{1}$, \\ XING-SHUN XU ${ }^{1,2}$, YA-PING YANG ${ }^{2}, \mathrm{JUN} \mathrm{LI}^{2}$ and CHUN-FENG LIU ${ }^{1,2}$ \\ ${ }^{1}$ Department of Neurology, Second Affiliated Hospital of Soochow University, Suzhou 215004; \\ ${ }^{2}$ Institute of Neuroscience, Soochow University, Suzhou 215123, P.R. China
}

Received November 22, 2010; Accepted March 9, 2011

DOI: $10.3892 / \mathrm{mmr} .2011 .460$

\begin{abstract}
Advanced glycation end-products (AGEs) contribute to the pathogenesis of diabetes mellitus and atherosclerosis by promoting vascular endothelial cell proliferation, migration, damage and death. In this study, we examined the role of autophagy in HUVECs exposed to AGE-modified bovine serum albumin (AGE-BSA). HUVECs incubated with AGE-BSA for $6 \mathrm{~h}$ showed an increase in the formation of acidic vesicular organelles and autophagosomes. AGE-BSA-induced upregulation of microtubule associated protein 1 light chain 3-II (LC3-II), a marker of autophagy, was abolished by pretreatment with the autophagy inhibitor 3-methyladenine (3-MA), and was increased by rapamycin, an autophagy inducer. The increase of lactate dehydrogenase (LDH) leakage induced by AGE-BSA was increased by 3-MA, but not rapamycin. An oxidative inhibitor, $\alpha$-tocopherol, decreased not only the AGE-BSA-induced increase of reactive oxygen species, but also the upregulation of LC3-II protein levels. These results suggest that AGE-BSA increases the level of autophagy, which is protective against HUVEC injury, and that ROS play a role in this activation of autophagy.
\end{abstract}

\section{Introduction}

Advanced glycation end-products (AGEs) are modified proteins or lipids that become nonenzymatically glycated and oxidized after contact with aldose sugars $(1,2)$. AGEs accumulate rapidly in different tissues (3) and play a role in the pathogenesis of various complications, particularly in the process of atherosclerosis (3-5). AGEs are located in the vessel wall and target the structure and functions of vascular endothelial cells

Correspondence to: Dr Chun-Feng Liu, Department of Neurology, Second Affiliated Hospital, Institute of Neuroscience, Soochow University, Suzhou 215004, P.R. China

Email: liucf@suda.edu.cn

*Contributed equally

Key words: autophagy, advanced glycation end-product-modified bovine serum albumin, reactive oxygen species, human umbilical vein endothelial cells, injury
(6-8); e.g., they induce endothelial cell proliferation and death, increase endothelial permeability, and induce the adhesion and migration of monocytes across the endothelial cell monolayer, thus prompting the development of atherosclerosis.

Autophagy is a physiological process in the routine turnover of cellular constituents and serves as a temporary survival mechanism during starvation, when self-digestion provides an alternative energy source. Autophagy has also been proposed to involve another biological function: the clearing of misfolded proteins under certain stress conditions $(9,10)$. Glycated collagen I (GC) is an important component of AGEs. It is reported that autophagic cell death is induced in human umbilical vein endothelial cells (HUVECs) treated with GC for $24 \mathrm{~h}$ (11). Oxidized low-density lipoprotein (ox-LDL) is also an oxidatively-injured protein involved in atherosclerosis (12). Our previous studies found that ox-LDL exposure $(100 \mu \mathrm{g} / \mathrm{ml})$ for $6 \mathrm{~h}$ activates the autophagylysosomal pathway, which reduces ox-LDL-induced cell injury and proliferation in HUVECs by degrading ox-LDL, thus playing a protective role in ox-LDL-induced cell death. However, the role of autophagy in AGE-induced HUVEC injury is still unknown.

It is well known that reactive oxygen species (ROS) induce autophagy (13). Moderate or low levels of ROS play a protective role by inducing autophagy to degrade aggregated proteins and injured organelles, while high levels of ROS induce cell death, which often involves apoptosis through caspase activation (14). ROS plays an important role in AGE-induced pathological consequences in endothelial cells, including apoptosis (15). However, it has yet to be reported whether ROS also plays a role in AGE-induced autophagy in HUVECs.

In the present study, to investigate the role of autophagy in the injury of HUVECs induced by AGE-modified bovine serum albumin (AGE-BSA), we examined the activation of autophagy after AGE-BSA exposure and the effects of an inducer and an inhibitor of autophagy and the oxidative inhibitor $\alpha$-tocopherol.

\section{Materials and methods}

Cell culture. HUVECs were purchased from the Cell Institute of the Chinese Academy of Sciences in Shanghai. The cells 
were cultured in DMEM (Gibco, USA), supplemented with $10 \%$ heat-inactivated fetal calf serum (Hyclone, USA), $44 \mathrm{mM}$ $\mathrm{NaHCO}_{3}, 4 \mathrm{mM}$ Hepes, and $2 \mathrm{mM}$ glutamine at $37^{\circ} \mathrm{C}$ in a humidified incubator containing $5 \% \mathrm{CO}_{2}$.

Preparation of AGE-BSA. AGE-BSA was prepared by incubating BSA with $0.5 \mathrm{M}$ glucose at $37^{\circ} \mathrm{C}$ for 6 weeks under sterile conditions, as described previously (16). After unincorporated sugars were removed by dialysis against phosphate-buffered saline (PBS), the glucose-modified high molecular weight materials were used as AGE-BSA. Non-glycated BSA was incubated under the same conditions as a control. The concentrations of AGE-BSA and control BSA were determined by the Bradford method.

Transmission electron microscopy (TEM). Cells were washed three times in PBS and fixed in 2.5\% PBS-buffered glutaraldehyde at $4^{\circ} \mathrm{C}$ for $1 \mathrm{~h}$. Postfixation was performed in $1 \% \mathrm{OsO}_{4}$ for $1 \mathrm{~h}$. The cells were dehydrated in an ethanol gradient and embedded in Araldite. Ultrathin sections $(40-60 \mathrm{~nm})$ were placed on grids (200 mesh) and double-stained with uranyl acetate and lead citrate. The sections were observed under a Philips CM-120 electron microscope.

Western blotting for microtubule-associated protein 1 light chain 3-II (LC3) and caspase-3. Protein concentration was determined with a BCA kit (Pierce, Rockford, IL). Equal amounts of protein $(30 \mu \mathrm{g})$ were mixed with $5 \mathrm{X}$ loading buffer, separated on $12 \%$ SDS-PAGE and then transferred to polyvinylidene fluoride membranes (Immobilon-P; Millipore). After blocking with 5\% milk in TBST, the blots were incubated with the primary antibodies at $4^{\circ} \mathrm{C}$ overnight, then washed and incubated with peroxidase-conjugated secondary antibodies (Vector Laboratories, Burlingame, CA) for $1 \mathrm{~h}$ at room temperature. Immunoreactivity was detected by enhanced chemiluminescence autoradiography (ECL, Amersham, Arlington Heights, IL). The densitometry of the bands was analyzed by SigmaScan Pro5 software. The intensity of each band was normalized to the loading control $\beta$-actin. Rabbit polyclonal anti-MAP-LC3 was from Abcam Biotechnology (USA); mouse polyclonal anti-caspase-3 was from Beyotime Biotechnology (China); mouse polyclonal anti- $\beta$-actin was from Santa Cruz Biotechnology (Europe).

Immunofluorescence. HUVECs $\left(1 \times 10^{4}\right)$ were seeded on circular coverslips (diameter $12 \mathrm{~mm}$; Fisher) in 24-well tissue culture plates (Corning, Inc.). Cultures were washed in PBS for $3 \times 5 \mathrm{~min}$ and fixed for $20 \mathrm{~min}$ in PBS containing $4 \%$ paraformaldehyde ( $\mathrm{pH}$ 7.4). After washing and blocking with PBS containing $1 \%$ normal BSA and $0.1 \%$ Triton$\mathrm{X}-100$ for $10 \mathrm{~min}$ at room temperature, the HUVECs were incubated with goat polyclonal anti-MAP1-LC3 antibody (Santa Cruz) at $4^{\circ} \mathrm{C}$ overnight. The cultures were subsequently washed and incubated with anti-goat $\mathrm{Cy} 3$ $\mathrm{IgG}$ antibody for $1 \mathrm{~h}$ at $37^{\circ} \mathrm{C}$. After rinsing several times, the cells were incubated with $10 \mathrm{mg} / \mathrm{ml} \mathrm{4-6-diamidino-2-}$ phenylin-dole (DAPI; Serva, Heidelberg, Germany) for $5 \mathrm{~min}$ at room temperature. Cultures were then mounted on glass slides with Vectashield Mounting Medium (Vector Lab) and analyzed under a confocal microscope (Leica,
Germany). Images were digitally analyzed using Leica microsystem software to quantify the fluorescence.

Apoptosis assay. Cells were harvested and centrifuged, and then the pellets were re-suspended in PBS. The cells were counted and $1 \times 10^{6}$ cells were incubated with Alexa Fluor 488 annexin V/propidium iodide from an apoptosis assay kit (Invitrogen Detection Technology, Eugene, OR). The number of apoptotic cells per $1 \times 10^{4}$ cells was counted.

Lactate dehydrogenase assay. To evaluate cell injury, lactate dehydrogenase (LDH) released from cells into the culture medium was measured with an assay kit (Nanjing Jiancheng Co., China) according to the manufacturer's instructions. In brief, $100 \mu \mathrm{l}$ cell-free supernatant, $250 \mu \mathrm{l}$ buffer, and $50 \mu \mathrm{l}$ coenzyme were mixed and incubated for $15 \mathrm{~min}$ at $37^{\circ} \mathrm{C}$, followed by the addition of $250 \mu 1$ 2,4-dinitrophenylhydrazine for another $15 \mathrm{~min}$ at $37^{\circ} \mathrm{C}$ in the dark. Finally, $2.5 \mathrm{ml} \mathrm{NaOH}$ $(0.4 \mathrm{M})$ was added to the reaction mixture. Three minutes later, $200 \mu 1$ of each reaction mixture was transferred into the wells of a new 96-well plate. The absorbance was determined at $440 \mathrm{~nm}$. Sample blank, standard and standard blank tubes were also measured. The activity of LDH was calculated according to the formula: LDH activity $(\mathrm{U} / \mathrm{L})=[$ (sample OD - sample blank OD)/(standard OD - standard blank OD)] x $2 \mu \mathrm{mol} / \mathrm{ml} \times 1,000 \mathrm{ml}$.

ROS measurements. 2',7'-Dichlorofluorescin diacetate (DCFH-DA) was added to cells at a final concentration of $20 \mu \mathrm{M}$. After $30 \mathrm{~min}$ of incubation, the cells were trypsinized and collected in phenol red-free RPMI medium. The fluorescence intensity of DCF, a compound formed in response to ROS, was detected by flow cytometry using CellQuest software (Beckman-Coulter, USA). The excitation and emission wavelengths were set at 488 and $530 \mathrm{~nm}$, respectively.

Statistical analysis. Data are presented as the mean \pm SD for at least three sets of independent experiments. Each experiment was carried out in duplicate. Differences between groups were assessed using one-way ANOVA with Scheffe's test. A p-value $<0.05$ was considered statistically significant.

\section{Results}

AGE-BSA induced autophagy in HUVECs. LC3 was the first protein identified on the autophagosomal membrane. After undergoing posttranslational modification (17), LC3-II, the product of LC3 conversion from LC3-I, is closely associated with the autophagosomal membrane and migrates faster than LC3-I on SDS-PAGE. Consequently, immunoblotting of LC3 detects two bands: LC3-I (18 kDa) and LC3-II (16 kDa). Because the amount of LC3-II correlates with the number of autophagosomes, immunoblot analysis of LC3-II is an easy method for predicting the autophagic activity of mammalian cells (18). This property was used to monitor the dynamics of the autophagic process in HUVECs exposed to AGE-BSA.

We first determined whether the autophagy level changed when HUVECs were treated with different concentrations of AGE-BSA for different times. It was found that the expres- 
A

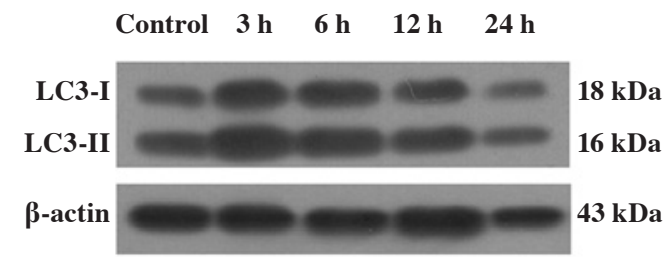

B

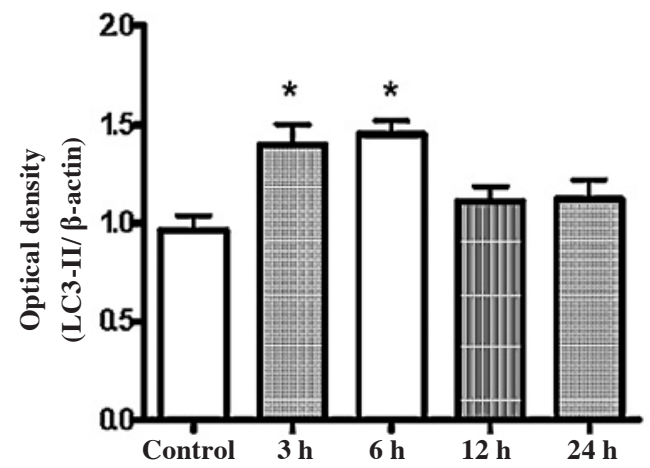

C

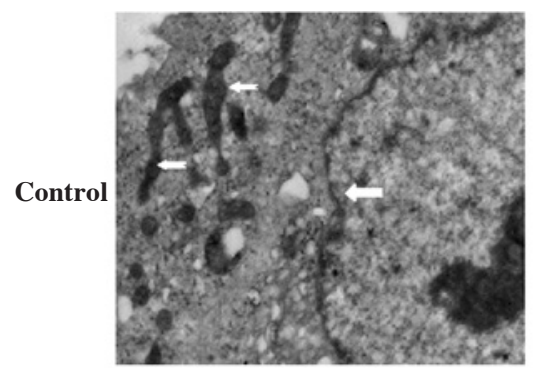

D

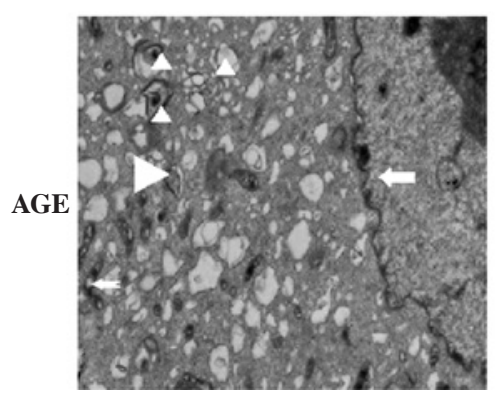

Figure 1. Enhanced autophagy in HUVECs after exposure to AGE-BSA. LC3-II protein levels were measured in HUVECs exposed to AGE-BSA (100 $\mu$ g/ml) for 3, 6, 12, or $24 \mathrm{~h}$. (A) Representative bands from Western blots showing LC3 protein levels after AGE-BSA treatment. $\beta$-actin was used as protein loading control. (B) Quantative analysis of the ratio of LC3-II to $\beta$-actin. ( ${ }^{*} \mathrm{P}<0.05$ vs. control). (C) Electron micrographs showing normal cytoplasm, mitochondria (thin arrows), nucleus (thick arrows) and no typical autophagosomes in the control group. (D) Increased autophagic vesicles were observed in HUVECs after AGE-BSA $(100 \mu \mathrm{g} / \mathrm{ml})$ treatment for $6 \mathrm{~h}$ (AGE). Typical autophagosomes with the characteristic double membrane were noted (triangle and thin arrows).

A

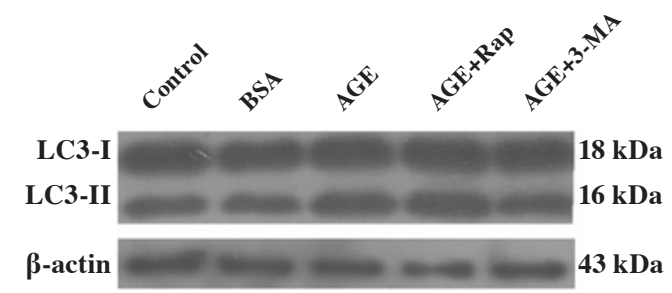

$\mathbf{B}$

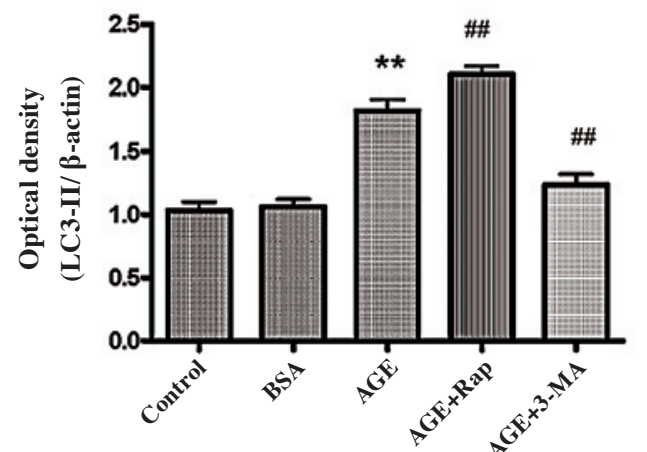

C

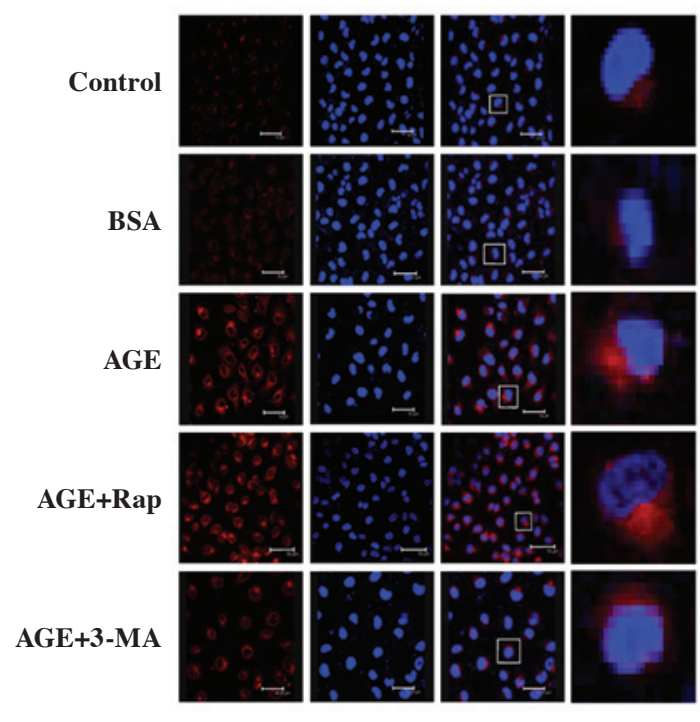

Figure 2. The autophagic level, increased by AGE-BSA, was blocked by 3-MA and further increased by rapamycin. HUVECs were treated with 3-MA $(10 \mathrm{mM})$ or rapamycin $(10 \mathrm{nM})$ for $30 \mathrm{~min}$, and then exposed to AGE-BSA $(100 \mu \mathrm{g} / \mathrm{ml})$ for $6 \mathrm{~h}$. The LC3 protein level was detected by Western blotting. (A) Representative bands of LC3 protein. (B) Quantitative analysis of LC3 protein $\left({ }^{* *} \mathrm{P}<0.01\right.$ vs. control, ${ }^{\# /} \mathrm{P}<0.01$ vs. AGE-BSA treatment). (C) After treatment, cultures were stained for MAP1-LC3 (red) and the nuclear marker DAPI (blue). Fluorescence micrographs showed that 3-MA decreased the AGE-BSAinduced autophagy level and rapamycin increased the AGE-BSA-induced autophagy level. Scale bar, $10 \mu \mathrm{m}$. AGE, AGE-BSA.

sion of LC3-II protein did not change in HUVECs exposed to $50-200 \mu \mathrm{g} / \mathrm{ml}$ of AGE-BSA for $6 \mathrm{~h}$ (data not shown), while time-course analysis of LC3-II protein showed that upregulation of the protein started at $3 \mathrm{~h}$ and then declined at $12 \mathrm{~h}$ after $100 \mu \mathrm{g} / \mathrm{ml}$ of AGE-BSA treatment (Fig. 1A and 1B).

TEM analysis is the conventional method for examining autophagy. Double membrane vesicles with identifiable cytosol components are the morphological manifestation of macroautophagy, while lysosomes with invaginations containing tubules or vesicles are a signature of microautophagy (19). TEM was therefore used to confirm the activation of autophagy by AGE-BSA. TEM images showed normal cytoplasm, mitochondria, nucleus and chromatin in control and BSA-treated HUVECs, while few or no autophagosomes and lysosomes were observed (Fig. 1C). In contrast, the TEM images from HUVECs treated with $100 \mu \mathrm{g} / \mathrm{ml}$ AGE-BSA displayed numerous autophagosomes at various stages of development (Fig. 1D). 
A

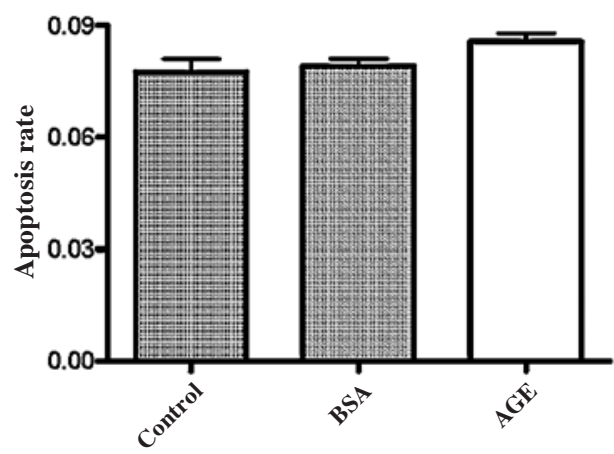

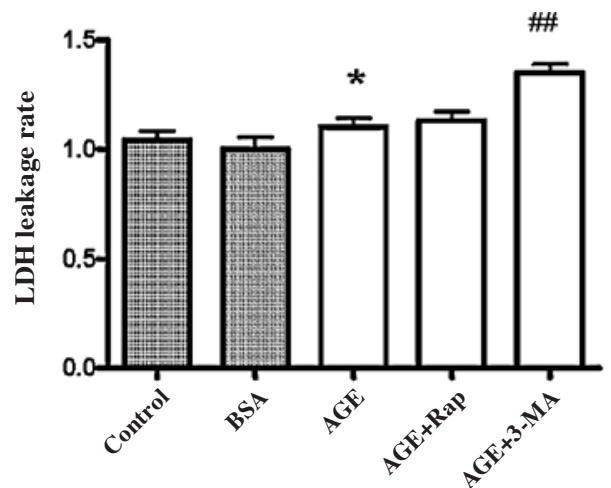

Figure 3. Autophagy, but not apoptosis, plays a protective role in AGE-BSA-induced HUVEC injury. (A) AGE-BSA did not induce apoptosis in HUVECs. After $6 \mathrm{~h}$ of exposure to $100 \mu \mathrm{mol} / \mathrm{ml}$ AGE-BSA, the percentage of Annexin V single-positive (early apoptosis) and Annexin V/PI double-positive (late apoptosis) cells did not differ from the control and BSA groups. (B) Protective effect of autophagy on the injury of HUVECs induced by AGE-BSA. The cells were treated with 3-MA $(10 \mathrm{mM})$ or rapamycin $(10 \mathrm{nM})$ for $30 \mathrm{~min}$ prior to $6 \mathrm{~h}$ of exposure to AGE-BSA $(100 \mu \mathrm{g} / \mathrm{ml})$. AGE-BSA-induced LDH release (a cell injury marker) was aggravated by 3 -MA, but not by rapamycin ("P<0.05 vs. control, ${ }^{\# \#} \mathrm{P}<0.01$ vs. AGE-BSA treatment). AGE, AGE-BSA.

A

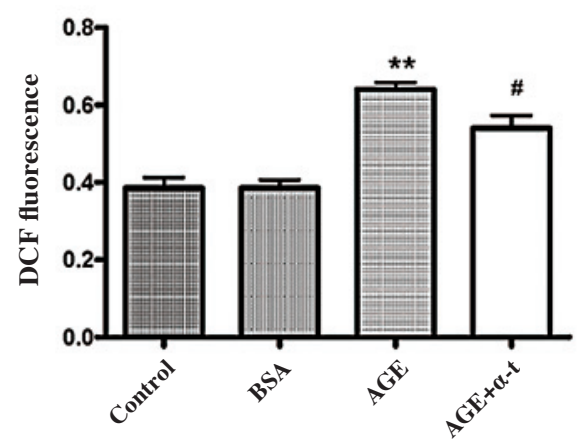

B

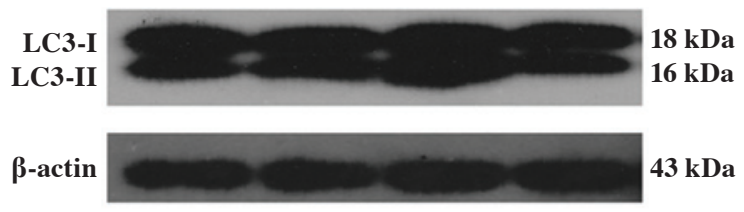

C

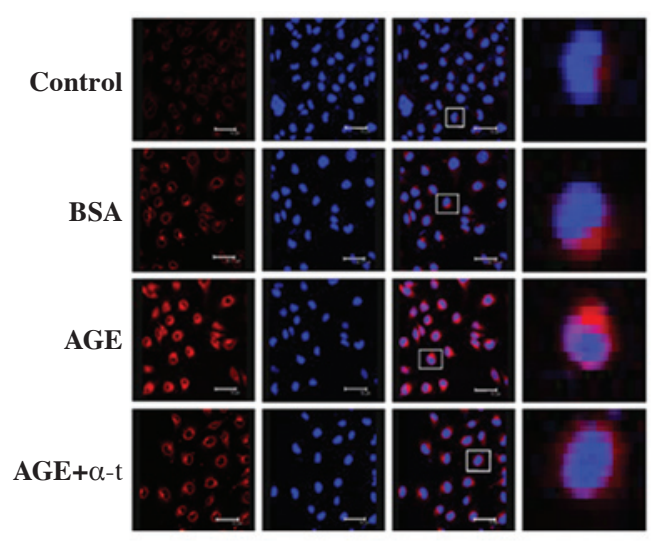

D

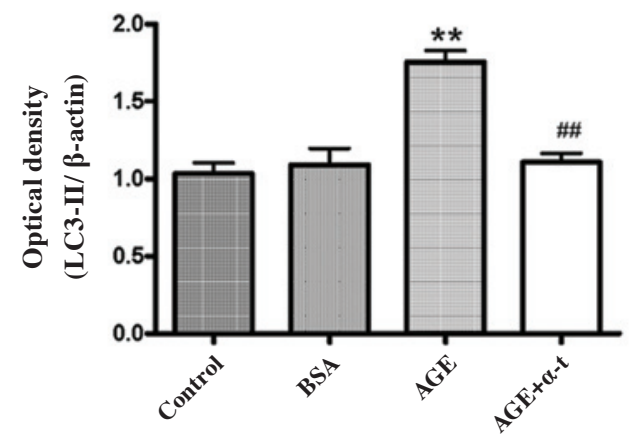

Figure 4. ROS mediated AGE-BSA-induced autophagy. (A) ROS levels in HUVECs with or without $\alpha$-tocopherol pretreatment $(15 \mu \mathrm{g} / \mathrm{ml})$ incubated with AGE-BSA $(100 \mu \mathrm{g} / \mathrm{ml})$ for $6 \mathrm{~h}$ was analyzed by DCFH-DA staining using flow cytometry. $\alpha$-tocopherol decreased AGE-BSA-induced ROS aggregation. $\left({ }^{* *} \mathrm{P}<0.01\right.$ vs. control, ${ }^{\# \#} \mathrm{P}<0.05$ vs. AGE-BSA treatment). (B) MAP1-LC3 expression levels in HUVECs with or without $\alpha$-tocopherol pretreatment $(15 \mu \mathrm{g} /$ $\mathrm{ml}$ ) incubated with AGE-BSA (100 $\mu \mathrm{g} / \mathrm{ml})$ for $6 \mathrm{~h}$. Cultures were stained with MAP1-LC3 (red) and the nuclear marker DAPI (blue). $\alpha$-tocopherol decreased AGE-BSA-induced MAP1-LC3 levels. Scale bars, $10 \mu \mathrm{m}$. (C). LC3-II protein expression levels in HUVECs with or without $\alpha$-tocopherol pretreatment (15 $\mu \mathrm{g} /$ $\mathrm{ml}$ ) incubated with AGE-BSA (100 $\mu \mathrm{g} / \mathrm{ml})$ for $6 \mathrm{~h}$. AGE-BSA-induced LC3-II protein expression levels were reversed by $\alpha$-tocopherol. (D) Autophagy level statistics of optical density measurements $\left({ }^{* *} \mathrm{P}<0.01\right.$ vs. control, ${ }^{\# *} \mathrm{P}<0.01$ vs. AGE-BSA treatment). AGE, AGE-BSA; $\alpha$-t, $\alpha$-tocopherol.

Inhibitor 3-methyladenine decreased AGE-BSA-induced autophagy. Recent studies have shown that 3-methyladenine (3-MA), an inhibitor of phosphatidylinositol 3-kinase, is capable of inhibiting autophagy (20), and that rapamycins can induce autophagy by the inhibition of mTOR (21). A previous study by our group showed that Ox-LDL increased the autophagic level. This increase was blocked by 3-methyladenine and increased by rapamycin (12).
The $6 \mathrm{~h}$ time point was selected to futher confirm whether the AGE-induced upregulation of autophagy was affected by 3-MA and rapamycin. HUVECs were treated with 3-MA $(10 \mathrm{mM})$ or rapamycin $(10 \mathrm{nM})$ for $30 \mathrm{~min}$ prior to the addition of AGE-BSA. Western blot analysis showed a significant increase of cleaved LC3-II in AGE-BSA-treated HUVECs. The addition of 3-MA returned LC3-II protein levels to almost control levels. By contrast, rapamycin aggravated the increase 
in LC3-II protein levels induced by AGE-BSA (Fig. 2A and 2B). This result was further confirmed by immunofluorescent staining (Fig. 2C).

Autophagy, not apoptosis, plays a protective role in HUVEC injury induced by AGE-BSA.

AGE-BSA did not induce apoptosis in HUVECs. AGEs have been reported to induce apoptosis in HUVECs at $48 \mathrm{~h}$ or later $(15,22)$. We investigated whether AGE-BSA induces apoptosis in HUVECs at the $6 \mathrm{~h}$ time point. Since active caspase- 3 is a biochemical marker of apoptosis, the active caspase-3 level was measured by Western blotting, and it was found that its levels did not differ between the AGE-BSA-treated and control groups (data not shown). This finding was confirmed by flow cytometry. The percentage of Annexin V single-positive (early apoptosis) and Annexin V/PI double-positive (late apoptosis) cells did not differ between the control, BSA and AGE-BSA groups (Fig. 3A).

Effect of rapamycin and 3-MA on AGE-BSA-induced $L D H$ increase in culture medium. It has been reported that AGE-BSA induces cell injury and death (22). We therefore determined whether AGE-BSA treatment for $6 \mathrm{~h}$ also induces HUVEC injury, and examined the role of autophagy in this AGE-BSA-induced cell injury. LDH leakage into the culture medium of AGE-BSA-treated cells was found to be higher than that of control cells. The increase of LDH leakage induced by AGE-BSA was enhanced by the autophagic inhibitor 3-MA, but not the autophagic inducer rapamycin (Fig. 3B). These data indicated that autophagy decreases AGE-BSA-induced cell injury. Therefore, we concluded that AGE-BSA-induced autophagy plays a protective role in AGE-BSA-induced cell injury.

AGE-BSA-induced autophagy is mediated by ROS.

Effect of AGE-BSA on HUVEC oxidative stress levels and anti-oxidant effect of $\alpha$-tocopherol. Next, we explored the mechanism of upregulation of autophagy. Recent studies have shown that AGEs induce ROS formation in certain cells $(1,23)$. Therefore, we investigated whether AGE-BSA treatment increases the ROS level in HUVECs. Using H2DCFDA-based detection by flow cytometry, ROS production was found to be increased in HUVECs incubated with AGE-BSA $(100 \mu \mathrm{g} / \mathrm{ml})$ for $6 \mathrm{~h}$ compared to control and BSA-treated cells (Fig. 4A). $\alpha$-tocopherol has antioxidant properties and decreases glycation LDL-induced oxidative stress (24). $\alpha$-tocopherol was found to effectively abrogate AGE-induced ROS accumulation in the HUVECs (Fig. 4A).

Effect of $\alpha$-tocopherol on increased autophagy induced by $A G E-B S A$. It has been reported that ROS acts as a signaling molecule in the activation of autophagy during nerve growth factor (NGF) deprivation (25) and starvation (15). We next determined whether ROS also plays a role in AGE-induced autophagy. Induction of autophagy by AGE-BSA was suppressed by $\alpha$-tocopherol treatment as detected by immunofluorescence staining (Fig. 4B) and Western blotting (Fig. 4C and 4D).

\section{Discussion}

The present study demonstrated that AGE-BSA treatment for $6 \mathrm{~h}$ did not increase apoptosis, but did induce autophagy in
HUVECs. The autophagy inhibitor 3-MA increased the cell damage induced by AGE-BSA, suggesting a protective role of autophagy in this injury. $\alpha$-tocopherol decreased intracellular ROS generation in HUVECs and reduced AGE-BSA-induced autophagy, indicating the critical role of ROS in the autophagic process.

In recent years, it has become accepted that autophagy, in addition to its role in cell survival, can also lead to cell death (referred to as type II cell death) $(10,26,27)$. First, autophagy promotes survival by generating the free amino acids and fatty acids required to maintain function during nutrient-limited conditions, or by removing damaged organelles and intracellular pathogens. Second, autophagy may also promote cell death through excessive self-digestion and degradation of essential cellular constituents. Glycated collagen I (GC) is an important component of AGEs. It was reported that autophagy is enhanced in HUVECs exposed to $100 \mu \mathrm{g} / \mathrm{ml} \mathrm{GC}$ for $24 \mathrm{~h}$, and that autophagy is a link between GC-induced apoptosis and the premature senescence of endothelial cells $(11,28)$. Since the autophagy induced by GC for $24 \mathrm{~h}$ contributes to cell death in HUVECs, we speculated that activation of autophagy in the early period may also play a protective role by promoting survival. Our present data from Western blotting, TEM images and immunofluorescent staining confirmed that autophagy was also induced in HUVECs by AGE-BSA in the early stage at the $6 \mathrm{~h}$ time point. In addition, we found that the autophagy inhibitor 3-MA aggravated AGE-BSA-induced cell injury.

A recent study showed that ROS play a role in the regulation of autophagy (13). The results of the present study suggest that ROS also play a role in the activation of autophagy induced by AGE-BSA. The antioxidant $\alpha$-tocopherol not only decreased AGE-BSA-induced ROS generation, but also reduced the upregulation of autophagy. Oxidative stress produced by mitochondria triggers one of several processes, depending on the severity of damage: mild damage induces mitophagy, which promotes cell survival through Uth1 in yeast and as yet unknown factors in mammals, while excessive damage induces autophagic cell death or triggers apoptosis in mammals by increasing the release of cytochrome c (29-31). The present study and our previous study indicate that autophagy induced by AGE-BSA and OX-LDL for $6 \mathrm{~h}$ plays a protective role due to mild oxidative damage; however, excessive oxidative damage produced by AGEs can induce both autophagic cell death and apoptosis $(11,15)$.

Taken together, these data show that autophagy in HUVECs is activated by AGE-BSA, and this activation plays a protective role in AGE-BSA-induced cell injury. We also found that AGE-BSA-induced ROS may be a signaling molecule contributing to the activation of autophagy. However, the mechanisms of AGE-induced ROS generation and the ROS-induced activation of autophagy is in need of further study. It is widely accepted that AGEs induce vascular cellular activation and inflammation mainly through interaction with specific receptors for advanced glycation end products (RAGE) (32), and some studies have demonstrated that ROS is generated by AGEs through RAGE (33). Recent research showed that RAGE sustains autophagy, promoting pancreatic tumor cell survival (34). Thus, the upregulation of autophagy by AGE-BSA may be effected through the RAGE-ROS pathway. 


\section{Acknowledgements}

This study was supported by Plans for Graduate Research and Innovation in Colleges and Universities of Jiangsu Province (no. CX09B_036Z) and the National Natural Science Foundation of China (no. 30870869). We also thank Professor I.C. Bruce for the critical reading of the manuscript.

\section{References}

1. Schmidt AM, Hori O, Brett J, Yan SD, Wautier JL and Stern D Cellular receptors for advanced glycation end products. Implications for induction of oxidant stress and cellular dysfunction in the pathogenesis of vascular lesions. Arterioscler Thromb 14: 1521-1528, 1994.

2. Singh R, Barden A, Mori T and Beilin L: Advanced glycation end-products: a review. Diabetologia 44: 129-146, 2001

3. Brownlee M, Cerami A and Vlassara H: Advanced glycosylation end products in tissue and the biochemical basis of diabetic complications. N Engl J Med 318: 1315-1321, 1988.

4. Bucala R and Cerami A: Advanced glycosylation: chemistry, biology, and implications for diabetes and aging. Adv Pharmacol 23: 1-34, 1992

5. Vlassara H, Fuh H, Donnelly $\mathrm{T}$ and Cybulsky M: Advanced glycation endproducts promote adhesion molecule (VCAM-1, ICAM-1) expression and atheroma formation in normal rabbits. Mol Med 1: 447-456, 1995

6. Brett J, Schmidt AM, Yan SD, et al: Survey of the distribution of a newly characterized receptor for advanced glycation end products in tissues. Am J Pathol 143: 1699-1712, 1993.

7. Morigi M, Angioletti S, Imberti B, et al: Leukocyte-endothelial interaction is augmented by high glucose concentrations and hyperglycemia in a NF-kB-dependent fashion. J Clin Invest 101: 1905-1915, 1998.

8. Sengoelge G, Fodinger M, Skoupy S, et al: Endothelial cell adhesion molecule and PMNL response to inflammatory stimuli and AGE-modified fibronectin. Kidney Int 54: 1637-1651, 1998.

9. Komatsu M, Waguri S, Ueno T, et al: Impairment of starvationinduced and constitutive autophagy in Atg7-deficient mice. J Cell Biol 169: 425-434, 2005.

10. Baehrecke EH: Autophagy: dual roles in life and death. Nat Rev Mol Cell Biol 6: 505-510, 2005.

11. Patschan S, Chen J, Polotskaia A, Mendelev N, Cheng J, Patschan D and Goligorsky MS: Lipid mediators of autophagy in stressinduced premature senescence of endothelial cells. Am J Physiol Heart Circ Physiol 294: H1119-H1129, 2008.

12. Zhang YL, Cao YJ, Zhang X, et al: The autophagy-lysosome pathway: a novel mechanism involved in the processing of oxidized LDL in human vascular endothelial cells. Biochem Biophys Res Commun 394: 377-382, 2010.

13. Chen Y and Gibson SB: Is mitochondrial generation of reactive oxygen species a trigger for autophagy. Autophagy: Dec 14, 2007 (E-pub ahead of print).

14. Pelicano H, Carney D and Huang P: ROS stress in cancer cells and therapeutic implications. Drug Resist Updat 7: 97-110, 2004.

15. Zhou YJ, Yang HW, Wang XG and Zhang H: Hepatocyte growth factor prevents advanced glycation end products-induced injury and oxidative stress through a PI3K/Akt-dependent pathway in human endothelial cells. Life Sci 85: 670-677, 2009.
16. Yamagishi S, Yonekura H, Yamamoto Y, et al: Advanced glycation end products-driven angiogenesis in vitro. Induction of the growth and tube formation of human microvascular endothelial cells through autocrine vascular endothelial growth factor. J Biol Chem 272: 8723-8730, 1997.

17. Yoshimori T: Autophagy: a regulated bulk degradation process inside cells. Biochem Biophys Res Commun 313: 453-458, 2004.

18. Kabeya Y, Mizushima N, Ueno T, et al: LC3, a mammalian homologue of yeast Apg8p, is localized in autophagosome membranes after processing. EMBO J 19: 5720-5728, 2000.

19. Mizushima N: Methods for monitoring autophagy. Int J Biochem Cell Biol 36: 2491-502, 2004.

20. Kanzawa T, Germano IM, Komata T, Ito H, Kondo Y and Kondo S: Role of autophagy in temozolomide-induced cytotoxicity for malignant glioma cells. Cell Death Differ 11: 448-457, 2004.

21. Bjornsti MA and Houghton PJ: The TOR pathway: a target for cancer therapy. Nat Rev Cancer 4: 335-348, 2004.

22. Yamagishi S, Inagaki Y, Okamoto T, Amano S, Koga K, Takeuchi M and Makita Z: Advanced glycation end productinduced apoptosis and overexpression of vascular endothelial growth factor and monocyte chemoattractant protein-1 in humancultured mesangial cells. J Biol Chem 277: 20309-20315, 2002.

23 Brownlee M, Vlassara $\mathrm{H}$ and Cerami A: Nonenzymatic glycosylation products on collagen covalently trap low-density lipoprotein. Diabetes 34: 938-941, 1985.

24. Mohammad AG and Samad M: In vitro effect of $\alpha$-tocopherol, ascorbic acid and lycopene on low density lipoprotein glycation. Iran J Pharm Sci 6: 265-271, 2007.

25. Kirkland RA, Adibhatla RM, Hatcher JF and Franklin JL: Loss of cardiolipin and mitochondria during programmed neuronal death: evidence of a role for lipid peroxidation and autophagy. Neuroscience 115: 587-602, 2002.

26. Codogno P and Meijer AJ: Autophagy and signaling: their role in cell survival and cell death. Cell Death Differ 12 (Suppl 2): 1509-1518, 2005.

27. Shintani T and Klionsky DJ: Autophagy in health and disease: a double-edged sword, Science 306: 990-995, 2004.

28. Patschan S and Goligorsky MS: Autophagy: The missing link between non-enzymatically glycated proteins inducing apoptosis and premature senescence of endothelial cells. Autophagy 4: 521-523, 2008

29. Lemasters JJ: Selective mitochondrial autophagy, or mitophagy, as a targeted defense against oxidative stress, mitochondrial dysfunction, and aging. Rejuvenation Res 8: 3-5, 2005.

30. Kissova I, Deffieu M, Manon S and Camougrand N: Uth1p is involved in the autophagic degradation of mitochondria. J Biol Chem 279: 39068-39074, 2004.

31. Lemasters JJ, Nieminen AL and Qian T: The mitochondrial permeability transition in cell death: a common mechanism in necrosis, apoptosis and autophagy. Biochim Biophys Acta 1366: 177-196, 1998

32. Bierhaus A, Illmer T and Kasper M: Advanced glycation end product (AGE)-mediated induction of tissue factor in cultured endothelial cells is dependent on RAGE. Circulation 96: 2262-2271, 1997.

33. Basta G, Lazzerini G, Del TS, Ratto GM, Schmidt AM and De Caterina R: At least 2 distinct pathways generating reactive oxygen species mediate vascular cell adhesion molecule-1 induction by advanced glycation end products. Arterioscler Thromb Vasc Biol 25: 1401-1407, 2005.

34. Kang R, Tang D, Schapiro NE, et al: The receptor for advanced glycation end products (RAGE) sustains autophagy and limits apoptosis, promoting pancreatic tumor cell survival. Cell Death Differ 17: 666-676, 2010. 